\title{
The Nottingham Health Profile as a measure of quality of life following combined heart and lung transplantation
}

\author{
B J O'BRIEN, ${ }^{1}$ N R BANNER, ${ }^{2}$ S GIBSON, ${ }^{2}$ AND M H YACOUB ${ }^{2}$ \\ From the Health Economics Research Group, ${ }^{1}$ Brunel University, Middlesex, and Harefield Hospital, ${ }^{2}$ Harefield, \\ Middlesex
}

SUMmaRY This paper reports on the use of the Nottingham Health Profile as a measure of patient quality of life before and after combined heart and lung transplantation at Harefield Hospital. A total of 125 profiles from 48 patients were analysed. In both section 1 and section 2 of the profile, large and statistically significant $(\mathrm{p}<0.05)$ improvements in quality of life were associated with transplantation. The profile proved easy to use either as part of an interview during assessment for transplantation or as a postal follow-up postoperatively.

A recent development in cardiothoracic surgery has been the advent of combined heart and lung transplantation. ${ }^{1}$ This procedure offers a new mode of therapy for patients with primary pulmonary hypertension, pulmonary vascular disease or parenchymal lung disease. The role of this form of therapy has not yet been established. Several factors need to be considered when evaluating such a procedure, including the effect on patient survival, symptoms, functional capacity and quality of life. The aim of this paper is to report on our initial experience using the Nottingham Health Profile (NHP) with heart-lung transplant recipients at Harefield Hospital.

\section{Patients and Methods}

As of January 1987 a total of 78 patients had undergone combined heart-lung transplantation at Harefield Hospital. The majority of these patients $(66.7 \%)$ were female and the mean age $( \pm S D)$ was $23.8( \pm 13 \cdot 1)$ years. A total of 48 patients completed the health profile as part of a larger interview at assessment for transplantation. The remaining $\mathbf{3 0}$ patients were ineligible for this study, mainly for reasons of age and nationality: the questionnaire has not been validated for use in foreign translation, ${ }^{2}$ and is therefore restricted to English-speaking patients; it also requires a minimum reading age of 12 years and hence is not applicable to young children. Of the 30 ineligible patients, $46 \%$ were overseas patients, $39 \%$ were paediatric cases and $14 \%$ were too ill prior to operation to partake in the study.
The study design was observational rather than experimental. In the absence of a randomised nontreatment comparison group the aim was to take repeated measures for each patient both before and after transplantation. Each patient's pre-transplant profile score therefore serves as a reference point for his or her subsequent scores. The NHP was administered by interview at assessment and at 3monthly intervals prior to operation. Post-transplant completion of the profile was by postal follow-up (self-completion) at 3,6 and 12 months after operation. Of the 48 patients who completed the pre-transplant profile, 32 had survived for three months or more at the time of study. Of those surviving, 28 patients completed the profile at 3 months post-transplant (response rate $88 \%$ ).

The Nottingham Health Profile (NHP) was devised by a team at the Department of Community Health at Nottingham University School of Medicine. ${ }^{34}$ It is a widely used and well validated method of assessing quality of life and has been used successfully in a number of treatment evaluations including coronary artery bypass surgery 5 and heart transplantation. ${ }^{67}$ The profile is an adjunct to traditional clinical measures. It is not intended to be a measure of disease but an indicator of limitations on health.

The NHP consists of two parts; Part I sets out to measure subjective health status by asking for yes/no responses to a carefully selected set of 38 simple statements relating to six dimensions of social functioning: energy, pain, emotional reactions, sleep, social isolation, and physical mobility. All statements 
relate to limitations on activity or aspects of distress. Statements in any given dimension have been weighted relative to each other and possible "scores" for each dimension range from zero to 100 . The weightings were elicited from a random population sample in Nottingham using the scaling method of paired comparisons developed by Thurstone. ${ }^{8}$ As part of the extensive reliability testing of the profile the Nottingham researchers also surveyed "normal" population responses to statements and hence determined reference scores by age and sex. ${ }^{9}$

Part II of the NHP relates to seven areas of task performance most affected by health: occupation, ability to perform jobs around the home, social life, sexual life, home life, hobbies and holidays. Respondents answer "yes" if their present state of health is causing problems in that area of life. Statements do not carry weights and results are presented simply as a count or percentage of affirmative responses.

Statistical methods employed in the analysis of profile responses all use non-parametric techniques. ${ }^{10}$

\section{Results}

Pre- and postoperative mean NHP dimension scores are presented in the Table. In all six dimensions there were large differences between pre-transplant (assessment) responses and the earliest post-transplant measurement at 3 months after operation. The Wilcoxon matched-pairs sign rank test indicated significant $(p<0.05)$ reductions in scores for patients who had completed profiles both at assessment and 3 months postoperatively. Analysis of profile scores at 6 and 12 months showed no significant difference compared to three months post-transplant (Friedman two-way analysis of variance for repeated measures, $\mathrm{p}>0 \cdot 1)$.

Data from Part 2 of the profile indicate that prior to transplant $77 \%$ of patients were experiencing problems with their paid employment due to their health, whilst at 12 months after transplant the proportion was $15 \%$. The pattern of reduced problems related to health following transplantation was the same for all seven areas of life covered by the profile. The McNemar test for repeated measures (assessment $v 3$ month post-transplant) indicated that such improvements are statistically significant $(\mathrm{p}<0.05)$.

The table also includes published male and female "normal" scores, in the age range of 25-29 years, taken from a random sample of respondents in Nottingham. ${ }^{9}$

\section{Discussion}

The data presented here represent our initial experience of the effect of combined heart-lung transplantation on quality of life. The results are consistent with the findings of Buxton et al ${ }^{6}$ for heart transplant recipients and give clear evidence of the large post-operative improvements in quality of life. Significant reductions in the scores for all six dimensions on Part 1 of the profile were found, confirming our clinical impression that the procedure results in a marked improvement in patient symptoms and function. Similar changes occurred in the proportion of patients experiencing problems identified by Part 2 of the profile. Changes in observed NHP scores also accorded well with clinical measures

Nottingham Health Profile: Sections I and II.

\begin{tabular}{|c|c|c|c|c|c|c|}
\hline & \multirow{2}{*}{$\begin{array}{l}\text { Pre-transplant } \\
\text { assessment } \\
(n=48)\end{array}$} & \multirow{2}{*}{$\begin{array}{c}3 \text { months } \\
\text { post-transplant } \\
(n=28)\end{array}$} & \multirow{2}{*}{$\begin{array}{c}6 \text { months } \\
\text { post-transplant } \\
(n=24)\end{array}$} & \multirow{2}{*}{$\begin{array}{l}12 \text { months } \\
\text { post-transplant } \\
(n=13)\end{array}$} & \multicolumn{2}{|c|}{$\begin{array}{c}\text { "Normal", } \\
\text { population" }\end{array}$} \\
\hline & & & & & Males & Females \\
\hline Section I: & \multicolumn{6}{|c|}{ Mean dimension score } \\
\hline Energy & $76 \cdot 0$ & $14 \cdot 5$ & $6 \cdot 2$. & $4 \cdot 7$ & $8 \cdot 6$ & 20.0 \\
\hline Pain & $17 \cdot 8$ & 8.7 & $2 \cdot 7$ & $2 \cdot 3$ & 1.6 & 2.8 \\
\hline Emotional reactions & $39 \cdot 2$ & 6.5 & $3 \cdot 3$ & $1 \cdot 2$ & $10 \cdot 3$ & $14 \cdot 7$ \\
\hline Sleep & 38.9 & 13.6 & $4 \cdot 2$ & 6.6 & 8.6 & 9.7 \\
\hline Social isolation & $32 \cdot 1$ & $10 \cdot 3$ & 5.0 & $3 \cdot 1$ & 5.6 & 6.9 \\
\hline Physical mobility & $51 \cdot 2$ & 13.4 & $3 \cdot 3$ & 3.4 & 1.6 & $2 \cdot 0$ \\
\hline Section II: & \multicolumn{6}{|c|}{ Percentage of patients experiencing problems due to their health } \\
\hline Occupation & $76 \cdot 6$ & $42 \cdot 9$ & $20 \cdot 8$ & $15 \cdot 4$ & $7 \cdot 0$ & $6 \cdot 3$ \\
\hline Jobs around the home & $76 \cdot 6$ & $28 \cdot 6$ & 16.7 & 0 & $6 \cdot 2$ & $13 \cdot 2$ \\
\hline Social life & $77 \cdot 1$ & $17 \cdot 9$ & $12 \cdot 5$ & 0 & 8.6 & $11 \cdot 3$ \\
\hline Home life & $40 \cdot 4$ & $14 \cdot 3$ & $8 \cdot 3$ & 0 & $8 \cdot 6$ & $16 \cdot 3$ \\
\hline Sex life & 65.9 & $28 \cdot 6$ & $8 \cdot 3$ & $15 \cdot 4$ & $6 \cdot 2$ & $23 \cdot 2$ \\
\hline Hobbies & $77 \cdot 1$ & $21 \cdot 4$ & $20 \cdot 8$ & $15 \cdot 4$ & $14 \cdot 1$ & $10 \cdot 1$ \\
\hline Holidays & 70.8 & $17 \cdot 9$ & 20.8 & $7 \cdot 7$ & 6.2 & 5.0 \\
\hline
\end{tabular}

1 Population normals for age range 25-29 taken from a random sample of 2173 individuals in Nottingham (see Hunt et al. ${ }^{9}$ ).

Wilcoxon test for repeated measures: $\mathrm{p}<0.05$ on all dimensions of Section I for patients who completed profiles at assessment and 3 months post-transplant. McNemar

Test for repeated measures: $p<0.05$ in all dimensions of Section II for patients who completed profiles at assessment and three months post-transplant. 
such as exercise capacity. Heart-lung transplant recipients display a similar exercise capacity to that of cardiac recipients in the first year after operation. ${ }^{11}$ Such improvement in exercise capacity is reflected by a reduction in the "physical mobility" NHP dimension score post-operatively.

Our results demonstrate a significant improvement in quality of life after transplantation. The "normal" values published by Hunt et $a l^{9}$ allow an informal comparison between the transplant patients and normal subjects. Although formal statistical tests cannot be performed, these data suggest that posttransplant quality of life can approach that of the general population.

Although data presented here cover a limited follow-up period, they do suggest that improvements in quality of life are sustained well beyond the initial post-operative period. A longer period of observation is required to ascertain whether the profile will prove sensitive to the effects of late complications of transplantation such as obliterative bronchiolitis. ${ }^{12}$ The NHP is now routinely given to candidates for heart or heart-lung transplantation at Harefield and at intervals post-operatively. As the transplant programme expands and more data become available it will be possible to undertake more detailed analysis of variance between patient sub-groups and over time.

The present study illustrates how the use of a simple health status indicator such as the NHP can provide valuable patient outcome data which are complementary to the more traditional "endpoints" of treatment evaluation such as survival. Such measures are increasingly being incorporated into clinical trial designs and other treatment evaluations, both in cardiovascular therapy ${ }^{13}$ and in other areas of medicine, ${ }^{14} 15$ as a valid and valuable component of patient outcome measurement.

\section{References}

${ }^{1}$ Reitz BA, Wallwork JL, Hunt SA et al. Heart-lung transplantation: successful therapy for patients with pulmonary vascular disease. $N$ Eng J Med 1982; 306: 557-64.
2 Hunt SM. Cross-cultural issues in the use of socio-medical indicators. Health Policy 1986; 6: 149-58.

${ }^{3}$ Hunt SM, McEwen J. The development of a subjective health indicator. Sociology of Health and Illness 1983; 2: 231-45.

${ }^{4}$ Hunt SM, McEwen J, McKenna SP. Measuring health status, Beckenham, Kent: Croom Helm, 1986.

${ }^{5}$ Wallwork J, Caine N. A comparison of the quality of life of cardiac transplant patients and coronary artery bypass graft patients before and after surgery. Quality of Life and Cardiovascular Care 1985; 1(7): 317-31.

${ }^{6}$ Buxton MJ, Acheson R, Caine N, Gibson S, O'Brien BJ. Costs and benefits of the heart transplant programmes at Harefield and Papworth Hospitals, DHSS Research Report No. 12, London: HMSO, 1985.

${ }^{7}$ O'Brien BJ, Buxton MJ, Ferguson BA. Measuring the effectiveness of heart transplant programmes: Quality of life data and their relationship to survival analysis. $J$ Chronic Dis 1987: 40, Suppl 1: 137s-153s.

${ }^{8}$ McKenna SP, Hunt SM, McEwen J. Weighting the seriousness of perceived health problems using Thurstone's method of paired comparisons. Int $J$ Epidemiol 1981; 10: 93-7.

${ }^{9}$ Hunt SM, McEwen J, McKenna SP. Perceived health: age and sex comparisons in community. $J$ Epidemiol Community Health 1984; 38: 156-60.

${ }^{10}$ Siegel S. Nonparametric statistics for the behavioural sciences. Kogakusha, Tokyo: McGraw Hill.

${ }^{11}$ Banner NR, O'Brien C, Fitzgerald M, Khaghani A, Yacoub MH. An evaluation of the cardiovascular response to dynamic exercise after combined heart-lung transplantation. J Coll Cardiol 1987; 9: 57A.

12 Burke M, Theodore J, Baldwin JC et al. Twenty eight cases of human heart lung transplantation. Lancet 1986; i: 517-9.

13 Wenger NK, Mattson ME, Furberg CD, Elinson J. Assessment of quality of life in clinical trials of cardiovascular therapies Am J Cardiol 1984; 54: 908-13.

${ }^{14}$ Croog SH, Levine S, Testa MA et al. The effects of antihypertensive therapy on the quality of life. $N E n g J$ Med 1986; 314: 1657-64.

15 Bombardier C, Ware J, Russell LJ, Larson M, Chalmers A, Reid JL. Auranofin therapy and quality of life of patients with rheumatoid arthritis Am J Med 1986; 81: 565-77. 